\title{
Building maintenance: a technology for resource conservation
}

\author{
M. Di Sivo \& D. Ladiana \\ Department of Technologies for Built Environment, \\ University "G. d'Annunzio" of Chieti and Pescara, Italy
}

\begin{abstract}
The Bruntland Report has for the first time formulated the concept of "sustainable development", defining it as "development able to meet current needs without compromising future generations' ability to meet their own needs"; such definition has emphasised not only the need to limit natural resources consumption and pollution emissions, but has also introduced the concept of (ethical) "responsibility" of man's action, both towards the natural environment and towards the anthropized one. Applying the sustainability objectives to the building process (project, construction, maintenance, management, decommissioning) - with the intention of reducing raw materials demand and wastes - forces one to reflect even on the maintenance process role. Maintenance can indeed be intended as a tool to build up a co-evolution project between man and nature, to be achieved by considering and managing maintenance-oriented buildings. Carrying out the maintainability requirement during the project phase becomes crucial since it guarantees, during the managing phase, that the maintenance intervention is carried out without any unforeseen or unpredictable collateral events characterized by a waste of financial and environmental resources. A number of researches and experimentations have been developed at the Department of Technologies for Built Environment in order to encourage the carrying out of the maintainability requirement during the project phase.
\end{abstract}

Keywords: building sustainability, design strategies, maintenance, maintenability, criteria. 


\section{Introduction}

Within the technological culture awareness has grown of the responsibility to give a contribution to the realization of a new development model, taking into account the delicate balances among anthropos, physis and teknè; in order to carry out such model, a crucial role is held by the capacity to activate a renewal based on a careful reflection upon the relationship between purposes and means.

In order to satisfy the needs, it becomes necessary to determine modalities that are not only effective but above all efficient, capable of optimizing the relationship between the employed means (natural, financial and human resources) and the obtained results (transformation/conservation of the built environment, safety, life quality etc).

The products of anthropic processes, more than being a collection of objects, are finally conceived - by dilating one's observation in space and time - as real energetic fluxes crossing our systems and creating unrulable processes.

The energy and matter flux crossing our systems to activate multiple processes is characterized by three critic phases: resource acquisition, production and use of goods and, at the final stage, disposal; if it is important to reduce the resource captation and the quantity of produced waste, it is also important to stop the current acceleration of the matter passage from resource to waste, by dilating as more as possible the good life time.

Within the architecture technology, with regard to the above three categories, the maintenance technology can give a fundamental contribution.

The necessity to stop, or at least to reduce, the waste of more and more limited and non renewable resources as well as to reduce the incalculable production of waste requires that technological research and experimentation should aim at the definition and control of compatible processes or at the achievement of sustainability goals by developing methods and tools directed to the implementation of an environmentally friendly building process (which guarantees a higher life quality by means of more careful planning in all the phases of resource absorption, to the realization and use of manufactures, and to their dismission).

In such a conceptual context, maintenance assumes a strategic role: the needs for a quality building basically find an answer in the maintenance approach, since it represents both the first tool for building knowledge (by means of which to carry out reliability and safety) and the strategic approach to sustainability (because it regulates the full life cycle). Maintenance can indeed act to slow down the passage from resource to waste, by dilating as more as possible the useful life time of components. The maintenance aiming at achieving a sustainable maximum system lifespan is substantially carried out by means of actions prolonging the life cycle. Indeed, the genesis and adjustment of a system should have as their primary objective the surviving of the system itself.

It is then necessary to define strategies, methods and tools meant to prolong the life cycle with a view to the resource preservation and to the maintenance/improvement of the building and still to build asset performances. 
The maintenance and care concepts, intended to preserve and re-qualify building and nature, have a great cultural impact since they require a deep attention towards the building and natural heritage as a strategic choice of civilization and development.

\section{Maintenance as a strategic vision}

Maintenance technology aiming at sustainability can have a highly strategic role. Ferracuti [11] defined the importance of maintenance from an environmental point of view in a study dating back to the 90's: "The recent interest in maintenance, which is new mainly within the many phenomena composing the physical-environmental changes of anthropized space, seems it has to be interpreted as an indication other from economical. On the contrary, it seems to acquire new meanings going beyond its current technical acceptation and significantly symbolizes a deep and apparently irreversible historical change. In such 'conjunction', somehow to be read as the end of the industrial age, maintenance and environment, or we should better say 'problematic maintenance' and 'problematic ecology', present many overlapping zones, almost until they identify and become each other's specification".

Such convergence still hasn't been carefully evaluated and translated into managing politics recognizing the strategic role of maintenance for sustainability purposes. Maintenance and sustainability have a lot in common: they share a sort of 'platform' of values and objectives meant to assume a significant position within post-industrial ideology and culture.

Maintenance is then becoming more and more important against the simple materials management supporting the productive process; moreover, the awareness of the limited resources asks for the definition of a specific role for the maintenance economy.

In such perspective, the challenge of the care and maintenance-preservation of built environment inserts itself into the change processes which are typical of post-industrial society, and combines itself with sustainability and humanization.

An important aspect is the achievement of quality objectives. Looking for a global quality is certainly a synonym of care and maintenance. Mercedes Bresso [2] describes the real meaning of such quality: "The way to give back quality to objects and to contrast (...) the tendency to disposability doesn't only consist in giving them back their beauty, but in another quality as well: permanence. Quality as a synonym of 'sense', which is care and maintenance. Not only movable assets are involved, but also real estate (houses, monuments) and the natural heritage: the richest societies in history have to guarantee maintenance to their own art towns and woods. Quality is strictly linked to the maintenance and care of the matters of the world".

In order to develop a concept of quality related to the theme of duration and maintenance, the introduction of the principle of a legal responsibility for objects - defined as “the seller's legal responsibility for damages caused by a defective object" (D.E. del 26.7.1985) - requires a complex management (damage management and prevention) and, in the meantime, the concepts of risk, 
438 Eco-Architecture III

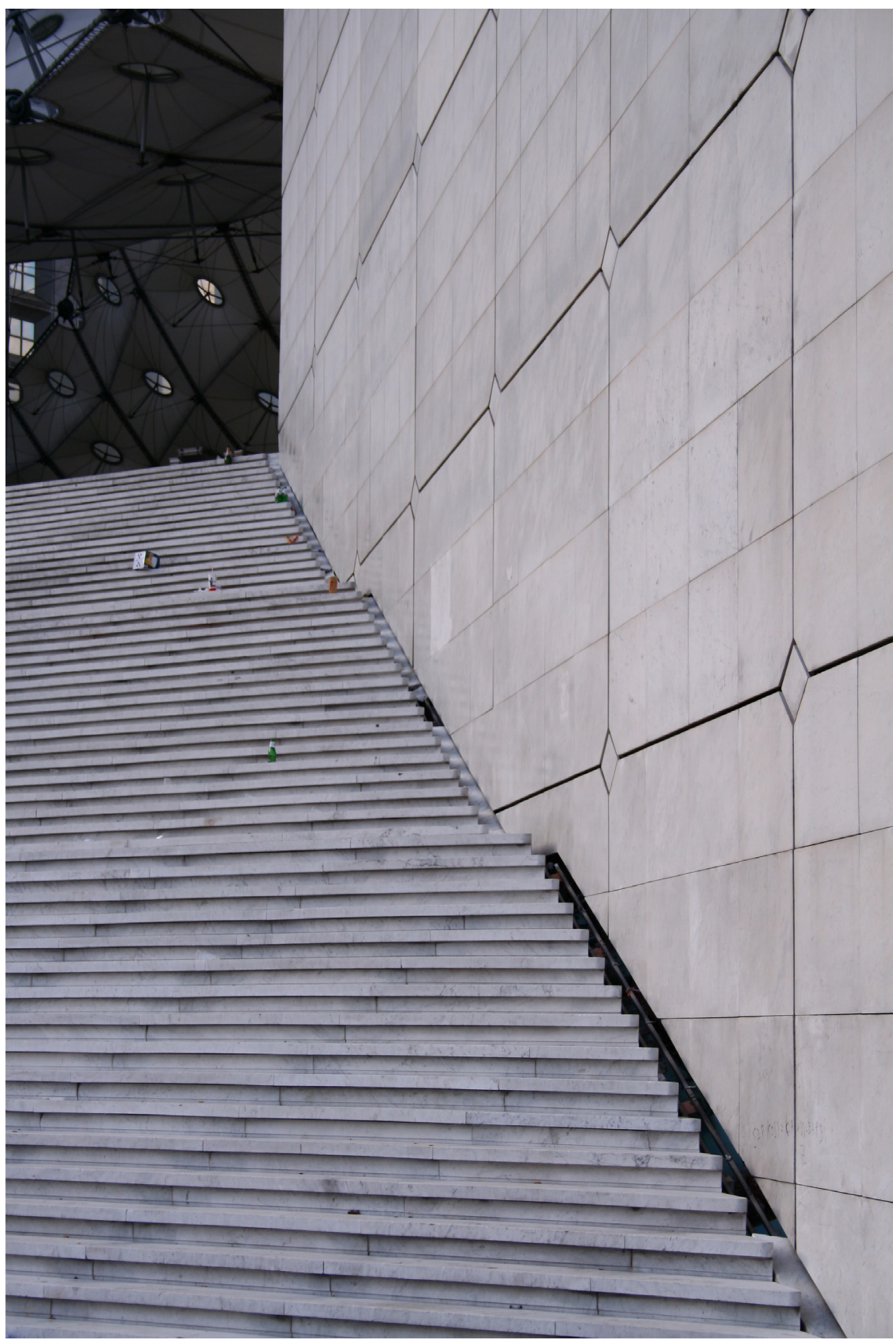

Figure 1: $\quad$ Paris, Grand Arche, self-cleaning capacity. 
reliability and maintainability as project requirements. Such principle represents causes and effects of a higher and higher demand. It is evident an expansion of the production cycle, which tends to extend to the relationships with the product users in order guarantee the best usage.

Within the market, the concept of 'product-service' has been more and more establishing itself having as a goal the quality maintenance even during usage. But, above all, a new role is taken by users - now considered as protagonists of the degradation process of used assets - who are now asked to undertake a direct responsibility in conservative interventions. The responsibility principle asks for the concept of service provided to users in order to increase the marginal utility of specific goods, in particular by means of maintenance interventions in as such way as they become 'excellence phenomena'.

In such a frame, maintenance should be interpreted as a complex process which replaces, and expands, the single random intervention. A great relevance is due not only to the purely technical aspects, but also to the interactions among users, so that the phenomenon assumes a socio-technical nature as well.

The same product to be maintained has to become a sort of socio-technical system because of the relationship to be established with users. Such a system expresses itself through a continuous process over time, explicating itself in different moments: the product realization, its conservation, its adjustment to the scenario where it typically stands.

Maintenance tends to become part of a "new science" which looks at the future highlighting the "purposes" in contraposition or, to better say, complementary to the "causes" determining the degradation phenomena as well as the obsolescence caused by use and ageing.

The time category can be considered as a context for analysing the possible convergences between maintenance technology and sustainability objectives. The research on the character of resource "permanence" and "conservation" guides us to re-discover the important care relationship with our environment, by means of a renewed approach to maintenance, intended as a crucial discipline to preserve the ecosystem balances.

Building maintenance represents a real strategy to govern complexity, aiming at the survival of all the built environment components; what is here underlined is that the maintenance approach represents the best it can be done for the care of building assets, being them traditionally different from the other assets because of a substantial specificity of their life-cycle: the service lifespan. Indeed, if the life-cycle of buildings is compared to the life-cycle of any industrial commodity or product, it is certainly among the longest; it is by exploiting this feature that maintenance can offer its most effective contribution to the macrosystems survival. If we consider a building and then evaluate, in terms of entropy balance, the phases of its life, it is possible to ascertain that the building reaches the highest positive entropy at the end of its construction, because of the great dissipation of energy and materials required; with time the building begins a transformation process whose velocity varies according to the varying physical characteristics of the constituting elements, of the environmental contest where it is set and of the use it is subjected to. 


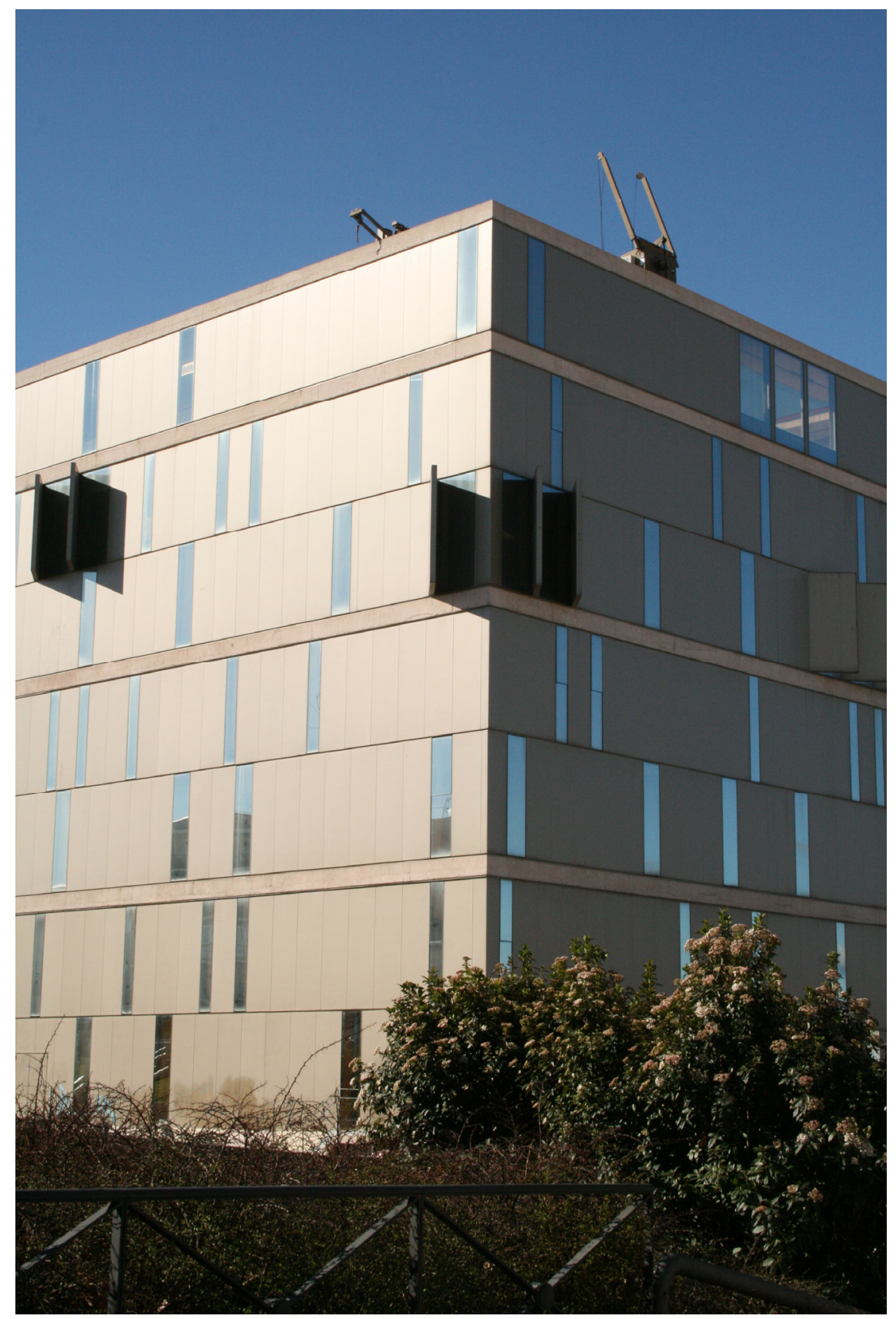

Figure 2: $\quad$ Madrid, Biblioteca de Usera, Facade access system. 
If it is not prevented, the process of dissolution, began in its most vulnerable parts, extends to the overall sub-system, resulting in partial or total use inefficiency. To benefit from the sub-system it is necessary to rebuild it by increasing entropy by up to the initial one; instead, if during its life cycle maintenance cycles have been planned, by means of small increases in entropy it is possible to obtain a more than significant life extension.

Maintenance as a disciplinary context aiming at regulating the system life cycles can offer an important contribution by pursuing, at any scale, the system lifespan extension.

\section{Integrating maintenance into the project}

System duration, resource saving, waste production abatement: these are the objectives which can give an efficient answer starting by integrating the maintenance approach into the projecting phase.

Table 1: $\quad$ Maintainability general criteria.

\begin{tabular}{|c|c|}
\hline $\begin{array}{l}\text { Distinction between } \\
\text { maintainability, } \\
\text { lifetime and } \\
\text { flexibility } \\
\end{array}$ & $\begin{array}{c}\text { Detailed and differentiated detection of the building elements (materials, } \\
\text { components, sub-systems), on the basis of which to pursue the lifetime, } \\
\text { maintainability and flexibility requirements. }\end{array}$ \\
\hline $\begin{array}{c}\text { Prevention from } \\
\text { degradation, wear, } \\
\text { physical } \\
\text { obsolescence }\end{array}$ & $\begin{array}{l}\text { Choice of building solutions suitable for preventing degradation, wear and } \\
\text { physical obsolescence of the building constituting elements, according both } \\
\text { to the external physical-environmental context where the building stands, } \\
\text { both to its functions and use modes. }\end{array}$ \\
\hline Lifetime congruence & $\begin{array}{l}\text { Congruence assessment of the lifespan of materials setting up the building } \\
\text { element or component. }\end{array}$ \\
\hline $\begin{array}{l}\text { Lifetime-flexibility } \\
\text { coherence }\end{array}$ & $\begin{array}{l}\text { Coherence test of the expected lifespan of elements with their needs and } \\
\text { predictions of space use flexibility over time, and with the related } \\
\text { consequences from a technical-operating point of view. }\end{array}$ \\
\hline $\begin{array}{c}\text { Technological } \\
\text { obsolescence and } \\
\text { flexibility }\end{array}$ & $\begin{array}{l}\text { Flexibility assessment of technical volumes intended for housing fixtures } \\
\text { and equipment, whose technological obsolescence is predictably quick. }\end{array}$ \\
\hline Inspectionability & $\begin{array}{l}\text { Inspectionability assessment of the drains - through which the technological } \\
\text { network and the spaces housing fixtures and equipment to be periodically } \\
\text { checked - pass. }\end{array}$ \\
\hline $\begin{array}{l}\text { Repairability, } \\
\text { demountability, } \\
\text { changeability }\end{array}$ & $\begin{array}{l}\text { Repairability, demountability and changeability assessment of elements } \\
\text { subjected to quick wearing or obsolescence process. }\end{array}$ \\
\hline $\begin{array}{l}\text { Functional non- } \\
\text { interference }\end{array}$ & $\begin{array}{l}\text { Non-interference assessment of the predictable maintenance activities } \\
\text { presenting functions or actions to be normally performed in an office. }\end{array}$ \\
\hline $\begin{array}{l}\text { Technical non- } \\
\text { interference }\end{array}$ & $\begin{array}{l}\text { It is assessed if the single components (or networks) maintenance can be } \\
\text { performed without impairing other systems or sub-systems functionality or } \\
\text { integrity. }\end{array}$ \\
\hline Demountability & $\begin{array}{l}\text { Assessment of the building system and sub-system level of demountability, } \\
\text { with particular attention to the "characteristics" and "state" on the part } \\
\text { connections. }\end{array}$ \\
\hline Testability & $\begin{array}{l}\text { Assessment of the testability level of sub-systems (especially the networks), } \\
\text { in order to allow the recognition of the "state" of functioning, degradation, } \\
\text { use and failure. }\end{array}$ \\
\hline
\end{tabular}


The utility of such an integration results from the necessity to provide conceptual and operational tools aiming not only at minimizing the process and building object impacts, but also at regulating the duration dimension of the process itself. It is indeed necessary to implement a building and construction process aiming at controlling the building life-span in order to expand as much as possible the useful phase.

The relationship operationally linking the concepts of duration and maintenance is an "inverse" relationship: the higher the product capacity to maintain unaltered characteristics over time, the lower the exigencies of maintenance intervention. Being linked to this close relationship, duration and maintenance should be simultaneously projected starting from the planning phase.

Table 2: $\quad$ Maintainability sub-requirements.

\begin{tabular}{|c|c|}
\hline Lifetime & $\begin{array}{l}\text { It is the requirement which enhances the technological system or the sub- } \\
\text { system to maintain its physical, performance and esthetical characteristics } \\
\text { unaltered over time. }\end{array}$ \\
\hline Non-soilability & $\begin{array}{c}\text { It is the requirement which enhances the sub-system or the technical element } \\
\text { to be hardly soilable, both for their intrinsic physical characteristics, both for } \\
\text { any morphological-technical devices (for example, the pyramid trunk over the } \\
\text { sixteenth century architraves of windows) }\end{array}$ \\
\hline $\begin{array}{l}\text { Self-cleaning } \\
\text { capacity }\end{array}$ & $\begin{array}{l}\text { It is the requirement which enhances the sub-system or component - } \\
\text { especially with regard to its form and project characteristics - to provide } \\
\text { autonomously, by using it or by means of the intervention of predicted or } \\
\text { projected factors, to its own cleaning (for example, the steps of external stairs } \\
\text { using rainwater to convey dirt to lateral drains). }\end{array}$ \\
\hline $\begin{array}{l}\text { Self-maintenance } \\
\text { capacity }\end{array}$ & $\begin{array}{l}\text { It is the requirement which enhances the sub-system to provide by its own to } \\
\text { the maintenance exigencies (for example, the self-lubrification). }\end{array}$ \\
\hline Cleanability & $\begin{array}{l}\text { It is the requirement which enhances the sub-system or component to be } \\
\text { easily cleaned, according to its morphological characteristics (for example, a } \\
\text { curve fitting instead of a sharp bend, or a tile instead of plaster). }\end{array}$ \\
\hline $\begin{array}{l}\text { User } \\
\text { maintainability }\end{array}$ & $\begin{array}{l}\text { It is the requirement which enhances the component or sub-system to be } \\
\text { maintainable by means of intervention which can be directly performed by the } \\
\text { user. }\end{array}$ \\
\hline Inspectionability & $\begin{array}{l}\text { It is the requirement which enhances the sub-system, system or component to } \\
\text { be easily inspected, even if periodically, in order to prevent or, in case of } \\
\text { failure, to verify the state of conservation or functionality and so to permit } \\
\text { repair or substitution (for example, networks of domestic fixtures). }\end{array}$ \\
\hline Repairability & $\begin{array}{l}\text { It is the requirement which enhances the sub-system, component or system to } \\
\text { be repaired by a user, an enterprise or an external maintainer. }\end{array}$ \\
\hline Demountability & $\begin{array}{l}\text { It is the requirement which enhances the component to be easily demounted } \\
\text { and removed from its usual collocation within the system it is part of, in order } \\
\text { to be repaired somewhere else; such a requirement can be complementary or } \\
\text { alternative to the requirement of "in situ" reparability. }\end{array}$ \\
\hline Replaceability & $\begin{array}{l}\text { It is the requirement which enhances the sub-system or component to be } \\
\text { easily replaced in case of irreversible failure or in case of functional or } \\
\text { technological obsolescence (for example, special attention should be paid to } \\
\text { the projecting of technical spaces intended for housing fixtures or equipments } \\
\text { prone to quick obsolescence. }\end{array}$ \\
\hline
\end{tabular}


A correct design should indeed makes choices which are conscious of the alternative - proposed for each material, component, sub-system - between a "long" life time (involving low maintenance) and a "limited" life time (involving higher levels of maintenance intervention). In this case, the project should also define modalities and contents.

A correct design should then formulate: conscious choices for each technological element of a manufactured, "project lifespan" (pre-valuable accordingly to the corresponding time and performance specifications) smartly integrated each other and systematically integrated with the corresponding predictions - which are project predictions as well - of the predictable maintenance interventions (in other words, of the maintainability characteristics of the product). For the purpose of the building system demounting and reuse/re-cycling of its constituent materials - once ended its life (or its usefulness, it is better to say) - it becomes convenient to predict the system constructive reversibility. In other terms, the asset design should include since its beginning a careful prediction of the morphologies and correlations which simplify demounting (which aims to maintenance and deconstruction, then to recycle or re-use).

Table 3: $\quad$ Maintainability and process variables.

\begin{tabular}{|c|c|}
\hline $\begin{array}{c}\text { Process } \\
\text { fragmentation }\end{array}$ & $\begin{array}{l}\text { Related to the organization of building production process, as well as the } \\
\text { possible responsabilization of the protagonists of the different process } \\
\text { phases (promoter, designer, builder, owner, user and maintainer) in relation } \\
\text { to maintenance needs. }\end{array}$ \\
\hline $\begin{array}{l}\text { Legal-trial-like } \\
\text { frame of the process }\end{array}$ & $\begin{array}{c}\text { Related to the procedure and contract specifications on how to set and } \\
\text { manage the productive process, and on how to evaluate and explicit the } \\
\text { impact anyone of the chosen legal-trial-like frames can have from the point } \\
\text { of view of future building asset maintainability }\end{array}$ \\
\hline Productive context & $\begin{array}{l}\text { Related to the economic, productive and technological characteristics of the } \\
\text { territory context, aiming at guaranteeing a concrete and contextualized } \\
\text { maintainability to the designed product, in other words at guaranteeing that } \\
\text { the product can be easily and economically maintained in that context. }\end{array}$ \\
\hline User profile & $\begin{array}{l}\text { It represents the set of variables - enjoyment title, spaces for private and } \\
\text { public use, user activity related to use - which highlight the building product } \\
\text { use modalities. All these variables involve a different attention to the } \\
\text { maintainability requirement (during planning and construction) and different } \\
\text { hypothesis for the user responsabilization during the definition of the } \\
\text { maintenance project. }\end{array}$ \\
\hline $\begin{array}{l}\text { Physical- } \\
\text { environmental } \\
\text { context }\end{array}$ & $\begin{array}{l}\text { It represents the set of variables caused by natural external agents (rain, hail, } \\
\text { snow, lightning, sun, organic agents, earthquakes, etc), by intrinsic agents } \\
\text { (moisture, chemical interaction among materials, etc), agents due to the } \\
\text { building use and management (physical-technical loads and over-loads, fire, } \\
\text { etc.) and by combined agents (rain and snow, acid rains, ultraviolet } \\
\text { radiations and rain etc), which can all represent a factor of degradation, wear } \\
\text { and physical obsolescence of the system or of the building technical } \\
\text { elements. }\end{array}$ \\
\hline
\end{tabular}


In comparison with the optimization of the building life cycle, implementing the requirement of maintainability represents one of the fundamental contributions that maintenance approach can give to a sustainability-oriented project.

Several researches and experimentations have been developed in Department of Technologies for Built Environment in order to achieve such a requirement during the project phase: indeed, the "general maintainability criteria", and the maintenance requirement resulting in "operating sub-requirements for the project" - to be adopted according to the internal characteristics of the project and to be joined to and used together with the "process variables" - represent a useful tool to give an ethical dimension to the building systems design.

In such a study approach it becomes evident not only how the subrequirement of maintainability represents the feature without which it is not possible to actuate solutions of use flexibility or to implement processes of constructive reversibility aiming to re-use and/or recycle at the end of the service life, but also how the concept according to which a maintenance intervention can be performed without having to develop other collateral unpredictable activities (characterized by depletion of economic and environmental resources) is part of the maintainability approach itself.

\section{Innovation scenarios}

In determining and controlling the extension of the building useful life cycle, the implementation of the maintenance process plays a crucial role, since its task is to prevent or remove degradation and obsolescence in order to guarantee functionality.

During the project phase, a maintenance-oriented approach in governing the life cycle duration requires, both for a new realization and for a re-qualification intervention, the implementation of the fundamental requirements of reliability, durability and maintainability.

The component reliability and the material durability allow one to reduce any possible failures and degradation, while maintainability facilitates the future interventions of maintenance without having to intervene upon close elements not subjected to failures. While projecting high levels of reliability and maintainability, in the managing phase the prediction will not be followed by a strong necessity of building maintenance interventions, simultaneously with an adequate maintainability level.

The implementation of the maintainability requirement permits to promote any possible re-qualification interventions necessary in case of an unbalance between the technical element performances and the users' changed exigency levels, allowing to make quick adjustment interventions upon the new levels of attended quality. The reversibility of the connections postulated by such a requirement also permits to decrease those impacts caused by building dismissal, since it allows to demolish with disassembling, and consequently to separate the constituting parts and the materials in order to their possible re-use or recycle. 
In the maintenance approach, it is implicit the concept that a maintenance intervention can be performed without any collateral predictable or unpredictable activities characterized by the waste of financial and environmental resources. In comparison with the building life cycle optimization, the implementation of the maintainability requirement represents one of the crucial contributions which the maintenance approach can give to a sustainability-oriented project.

Within the government context and within the building elements life cycle extension, it is evident the presence of numerous and important new paths toward product and process innovation.

With regard to products, the necessity to contain the maintenance intervention frequency requires a renewed interest in the implemented materials lifespan, whose knowledge is really little, as well as in the innovation of building components functional to the constituting parts lifespan congruence. The relationships among the constituting parts have to be consistent with their own maintenance life cycles, so that interventions on components characterized by a shorter lifespan don't have to necessarily involve interventions upon those components having a longer lifespan; in such a way, all components could be replaced only at the end of their own life cycle.

The improvement of the overall lifespan performances, for example in an attic, can be obtained by verifying the single layers performances and the study of alternative techniques to optimize synergies and relationships.

In addition to paying attention to the relationships among materials, it is relevant their number reduction as well: the existence of materials each of which characterized by a specific lifespan and maintenance mode multiplies the forms and frequencies of intervention; a reduced variety of materials reduces and simplifies the number of replacement cycles.

Another interesting theme, often queued, is given by the necessity of a substantial re-thinking of the connection modes between the building parts and components, in order to guarantee their own reversibility in a manner that facilitates both the maintenance and the re-qualification interventions. The development of clean execution technologies can allow "the possibility of linguistic flexibility and the building reversibility as well, both of them to be considered as fundamental paradigms in a building vision which considers the overall building life cycle - from the project phase up to the management, maintenance and disposal - its constituting components and materials." (Campioli [3]).

An innovating process context concerns the development of methods and tools based on low cost technologies for diagnostic and monitoring processes supporting decisional processes related to interventions on buildings which require a deep knowledge of the material and constitutive nature and of any possible changes undergone over time.

Having such information can allow one to optimize the decisional processes and minimize superfluous actions or interventions that are not useful. 


\section{Conclusions}

The research of the "permanence" and "resource conservation" character leads us to re-discover the important care relationship with our environment by means of a renewed approach to maintenance, conceived as a crucial discipline to regulate complex anthropic systems, and aiming not only at their own efficiency but also at the ecosystems balance preservation.

The necessity to implement a more careful lifespan regulation represents the main element, which is more associated with the maintenance culture than with the sustainable one, within an ideological and ethical dimension.

System lifespan, resource saving, waste abatement are the goals which, within the building system, can find an effective answer in the adoption of a maintenance approach during the project phase.

(Di Sivo Michele is the author of Sections 1 and 2; Ladiana Daniela of Sections 3 and 4)

\section{References}

[1] Ashby, W. R., Introduzione alla cibernetica, Einaudi, Torino, 1971.

[2] Bresso, M., Per un'economia ecologica, Nis, Roma, 1993.

[3] Campioli, A., Il contesto del progetto, Franco Angeli, Milano, 1993.

[4] Ciribini, G., Introduzione alla tecnologia del design, Franco Angeli, Milano. 1979.

[5] Ciribini, G., Tecnologia e progetto - Argomenti di cultura tecnologica della progettazione, Celid, Torino, 1984

[6] Directorate General for Development Evaluation Unit, Commission of the European Communities, Project Cycle Management Handbook, Geneve, March 2002.

[7] Di Sivo, M., Ladiana, D., Sicurezza e manutenzione dell'ambiente costruito, Alinea Editrice, Firenze, 2007.

[8] Di Sivo, M., Manutenzione Urbana, Alinea, Firenze, 2004.

[9] Dioguardi, G., I sistemi organizzativi, Bruno Mondadori, Milano. 2004.

[10] Dioguardi, G., Manutenzione d'eccellenza come strategia d'innovazione, In XX Congresso Nazionale AIMAN (Bologna, 20-21 February), 2003.

[11] Ferracuti, G., Tempo, qualità, manutenzione. Scritti sulla manutenzione edilizia, urbana e ambientale, Alinea, Firenze, 1994.

[12] Ladiana, D. (a cura di), Manutenzione e gestione sostenibile dell'ambiente urbano, Alinea Editrice, Firenze, 2007.

[13] Ladiana, D., Pianificazione della gestione e manutenzione delle infrastrutture urbane. L'approccio top-down e bottom-up, Alinea Editrice, Firenze, 2008. 